\title{
A TRAINING SYSTEM BASED ON VIRTUAL ENVIRONMENTS TO PREVENT INCIDENTS AND REDUCE ACCIDENTS DURING DECOMMISSIONING OF NUCLEAR FACILITIES
}

\author{
KWANSEONG JEONG, BYUNGSEON CHOI, JEIKWON MOON \& JONGWON CHOI \\ Korea Atomic Energy Research Institute
}

\begin{abstract}
Decommissioning of nuclear facilities should be accomplished by assuring the safety of workers because these decommissioning activities take place under high radioactivity and difficult work conditions. Before decommissioning, it is necessary to evaluate and assess the radiation exposure dose of workers under the principle of ALARA (as low as reasonably achievable). Furthermore, to improve the proficiency of decommissioning environments, methods and systems need to be developed. The legacy methods of exposure dose measurement and assessment have the limitations to modify and simulate the exposure dose of workers prior to practical activities because those should be accomplished without changes of working routes under predetermined scenarios. To simulate many decommissioning scenarios, decommissioning environments were designed in virtual reality. To simulate and assess exposure dose of workers, a human model was also designed in a virtual environment. These virtual decommissioning environments made it possible to simulate and assess in real time the exposure dose of workers. It can be concluded that this system is able to protect workers from accidents and enable them to improve their familiarization about their working environment. This system is expected to reduce human errors because workers can improve their proficiency of hazardous working environments due to virtual training like real decommissioning situations. In the end, safety during decommissioning of nuclear facilities will be guaranteed under the principle of ALARA.

Keywords: decommissioning, nuclear facilities, safety assessment, virtual environments.
\end{abstract}

\section{INTRODUCTION}

Decommissioning of nuclear facilities must be accomplished by assuring the safety of workers because these decommissioning activities take place under high radioactivity and difficult work conditions. Before decommissioning, it is necessary to analyse and assess radiation exposure dose of workers under the principle of ALARA (as low as reasonably achievable) [1].

The legacy methods of exposure dose measurement and assessment had the limitations to modify and simulate the exposure dose to workers prior to practical activities because those should be accomplished without changes of working routes under pre-determined scenarios.

This paper is intended to suggest a method to assess exposure dose of workers in virtual decommissioning environments. To simulate decommissioning scenarios, decommissioning environments were designed in virtual reality. To simulate and assess exposure dose of workers, a human model was also designed in a virtual environment. These virtual decommissioning environments made it possible to simulate and assess in real time the exposure dose of workers. 


\section{DEVELOPMENT OF TRAINING SYSTEM FOR DECOMMISSIONING WORKERS}

The training system for decommissioning workers was developed as shown in Fig. 1. When a worker places a head-mounted display (hereafter 'HMD') on his head, the graphic server of the virtual training system is being operated. This graphic server receives data of the worker's changing direction. It also exchanges data management units with the detected numerical data. The graphic server provides the HMD with pictures of direction response and the monitoring device with pictures of worker's location and behaviour. In this situation, the worker is in first person mode and can recognize decommissioning scenarios with the HMD as ones of working in place. On the other hand, the manager is in third person mode and can keep up with the worker's location and working situation.

\section{THE VIRTUAL DECOMMISSIONING ENVIRONMENTS}

To simulate several decommissioning scenarios, testing environments were designed in virtual reality. The development environments were based on a digital decommissioning mock-up [2]. Additionally, many scenarios were developed in 3D virtual environments to evaluate through dynamic simulation.

The virtual decommissioning environments were developed with Unity3D and were composed of three design phases: 3D mapping, scenario development, and radiation mapping. Figure 2 shows that a reactor is being mapped as 3D data. Figure 3 illustrates the scenario development of fulfilling a reactor pool, and Fig. 4 presents radiation mapping of a reactor. Radiation mapping refers to the amount of dose distribution in a reactor. The raw data of dose distribution can be obtained from the MCNP (Monte Carlo N-Particle Transport) code.
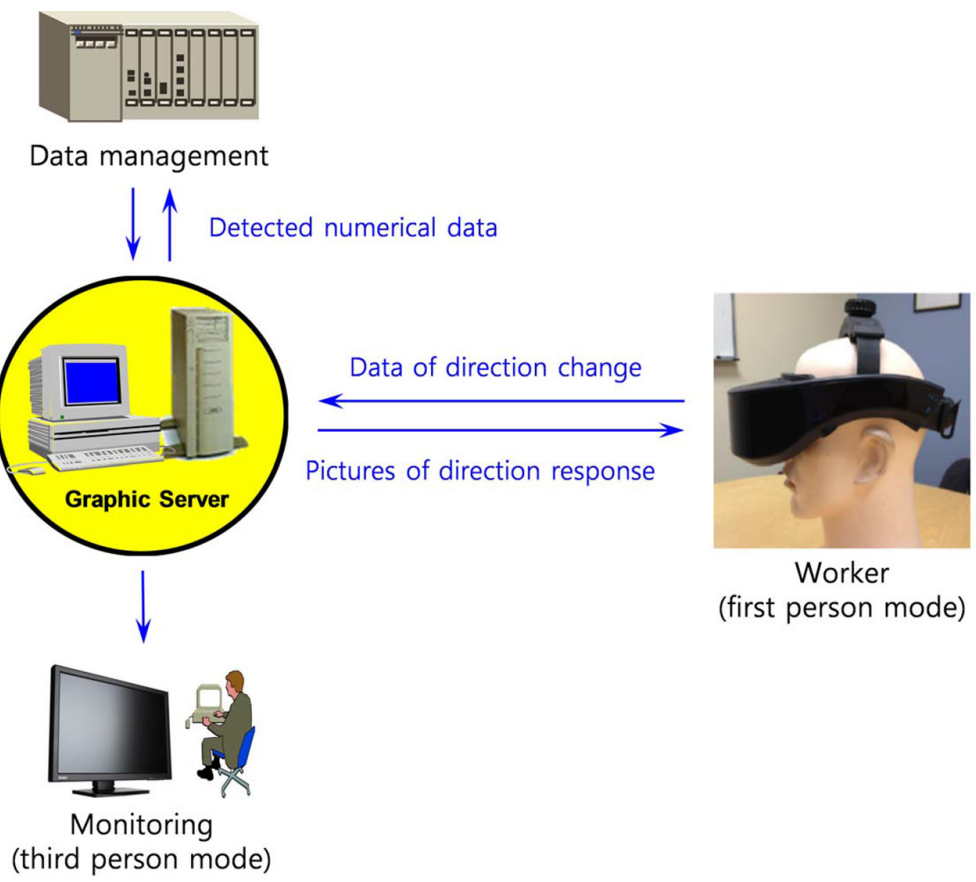

Figure 1: Conceptual design for the training system. 

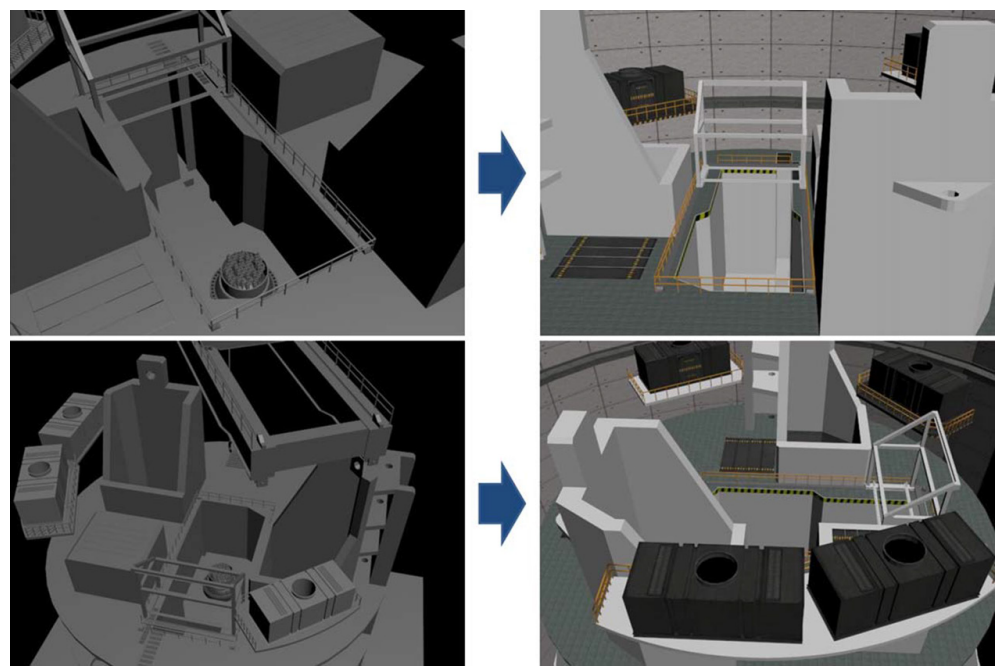

Figure 2: The 3D mapping environments of a reactor component.

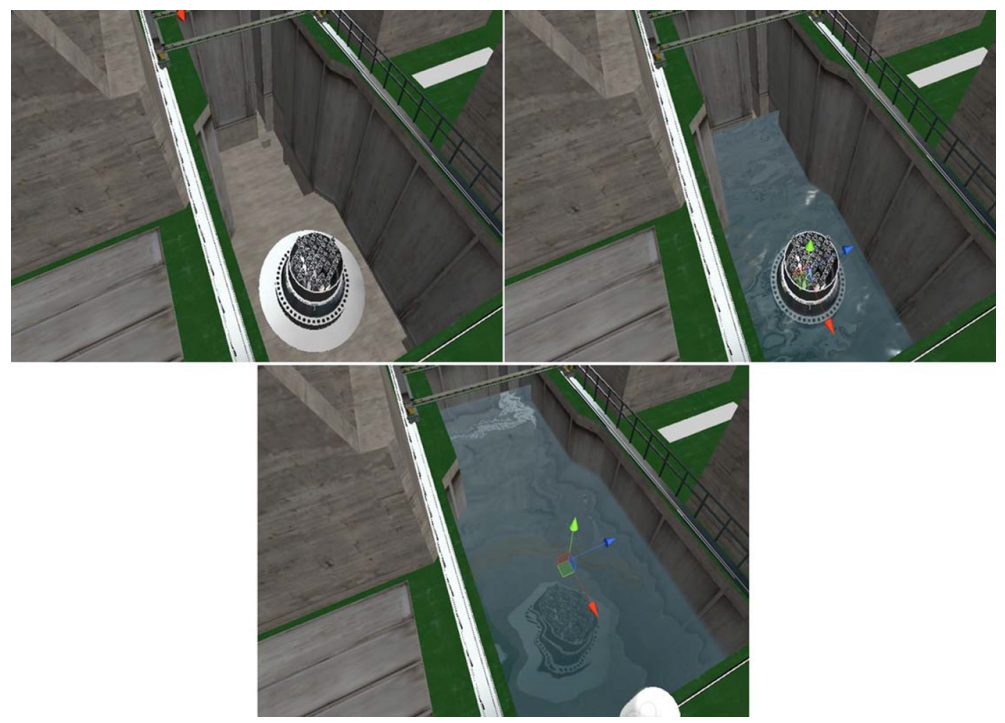

Figure 3: 3D mapping environments of a decommissioning scenario.

\section{THE HUMAN MODEL IN THE VIRTUAL DECOMMISSIONING ENVIRONMENTS}

\subsection{Configuration of the human model}

The human model in the virtual decommissioning environments has a feature of detecting the amount of collision between the human model and exposure dose distribution [3]. The scope of collision between the human model and exposure dose distribution is $20 \mathrm{~cm}$ in radius, and 


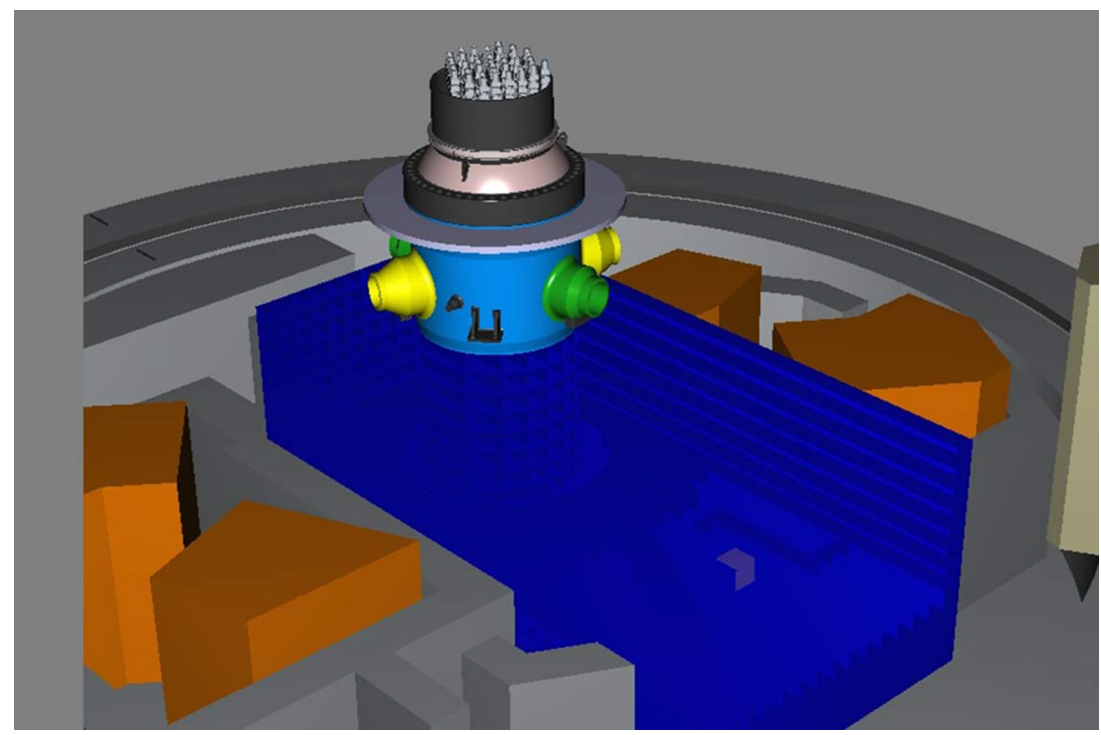

Figure 4: The 3D radiation mapping environments within a reactor.

the height of human model is $175 \mathrm{~cm}$ as shown in Fig. 5. Figure 6 displays the specification of the human model in the Unity3D tool.

\subsection{Visualizations of exposure dose level}

To visualize the exposure dose levels of the human model, they were classified using colours as presented in Fig. 7 and developed as cubes in the Unity3D tool. The size of each cube was $50 \mathrm{~cm}$. Figure 8 presents the specifications of a cube in the Unity3D tool. This classification of cubes can be modified depending upon radiological situations.

\subsection{Measurement of exposure dose of the human model}

Collision situations in virtual environments occur when the human model overlaps with the character controller in the Unity3D tool and box collider in the cube. When a worker moves in a virtual decommissioning environment, the human model enters the workplace surrounding dose distribution. At this time, the human model collides with multiple cubes in the virtual environment; the last cube is adopted and exposure dose can be obtained from values of the last cube, as shown in Fig. 9. When a collision occurs at the green line as seen in Fig. 9, the OnTriggerEnter function in Unity3D is called and the exposure dose in the cube is transferred into the human model. The evaluation of collision is computed by every frame and value of exposure dose is transferred into the human model every one second.

\section{ASSESSMENT OF EXPOSURE DOSE OF WORKERS IN VIRTUAL DECOMMISSIONING ENVIRONMENTS}

\subsection{Algorithm of exposure dose measurement}

In virtual decommissioning environments, the exposure dose of workers is measured by the performing cube, human mode, and user interface in the Unity3D tool, as shown in Fig. 10. 


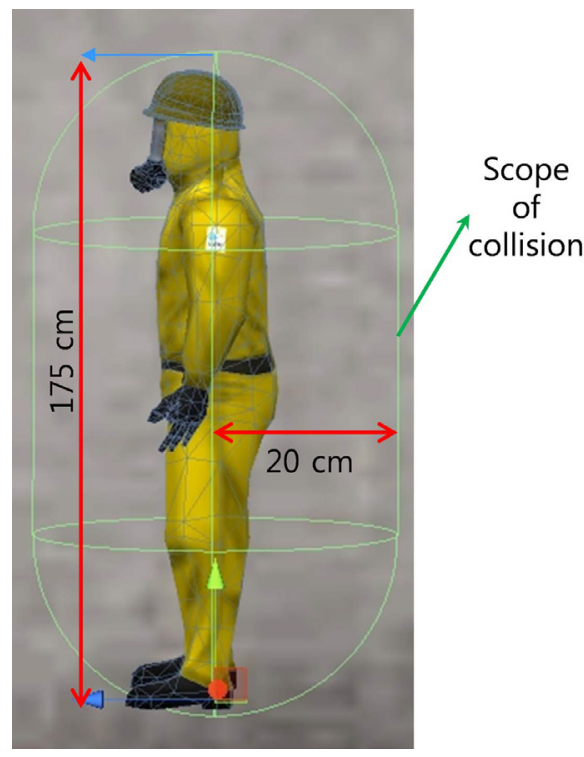

Figure 5: The human model in virtual environments.

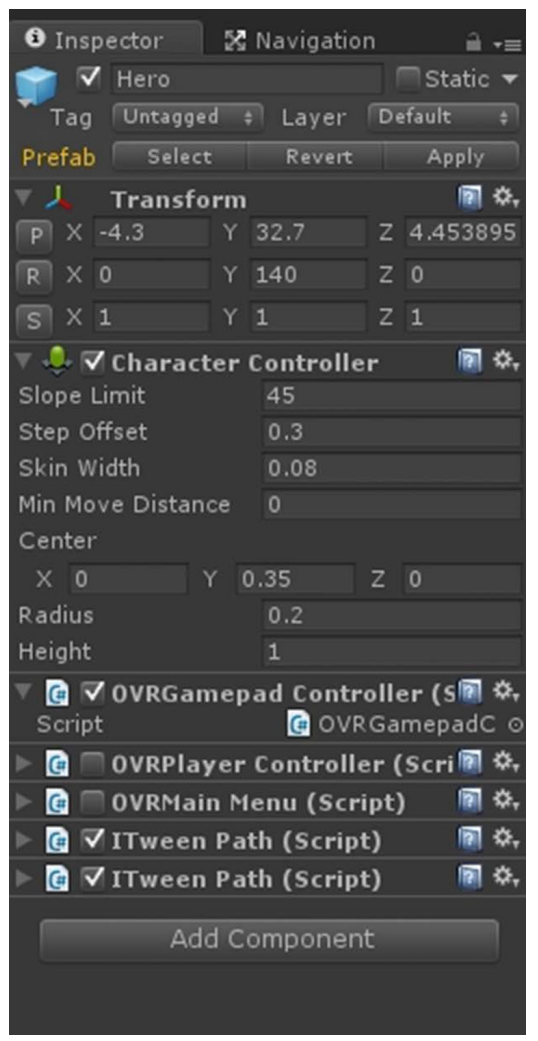

Figure 6: Specifications of the human model in the Unity3D tool. 


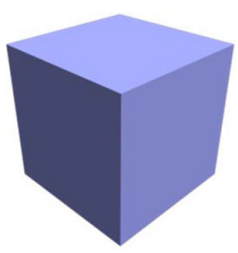

$$
0 \sim 1 \mathrm{mSv}
$$

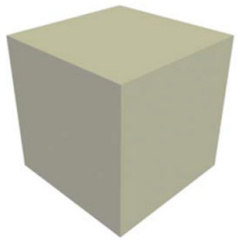

$10 \sim 20 \mathrm{mSv}$

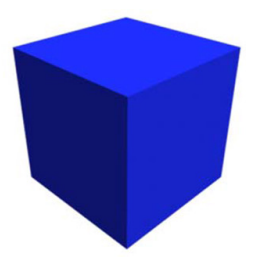

$1 \sim 5 \mathrm{mSv}$

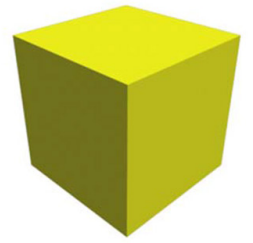

$20 \sim 30 \mathrm{mSv}$

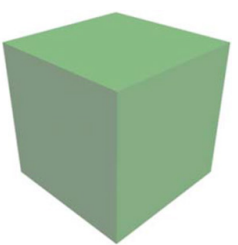

$5 \sim 10 \mathrm{mSv}$

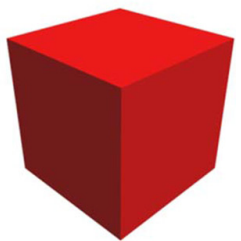

$>30 \mathrm{mSv}$

Figure 7: Classification of cubes in the Unity3D tool.

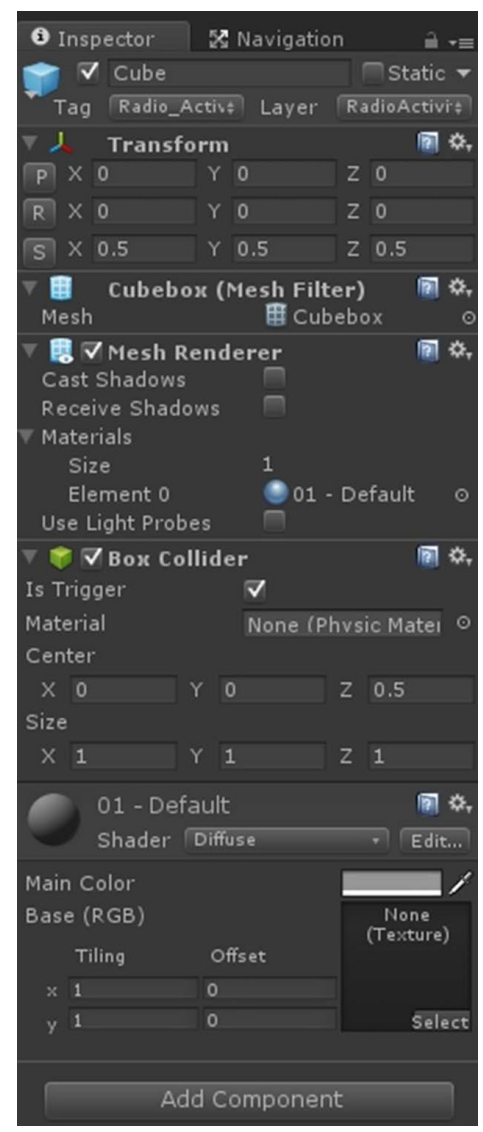

Figure 8: Specifications of a cube in the Unity3D tool. 

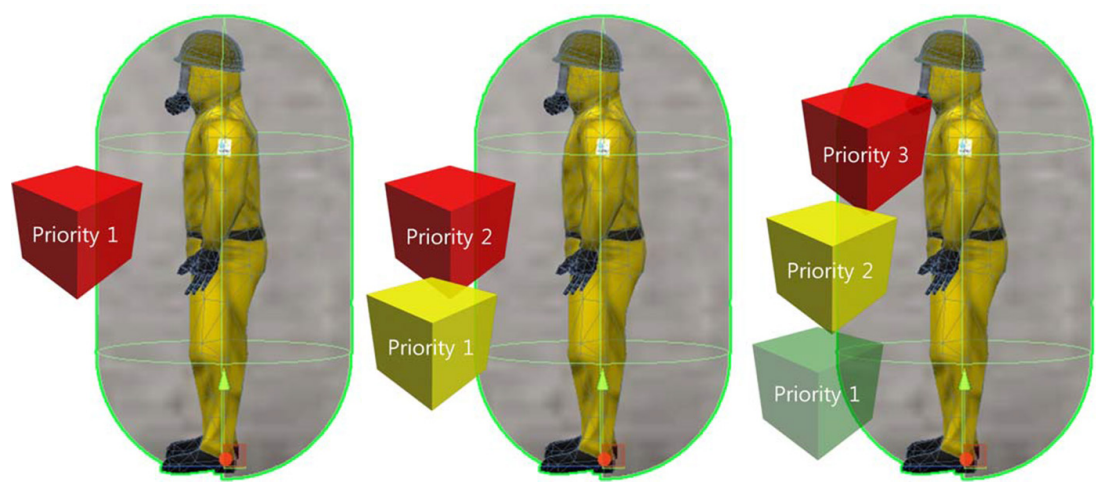

Figure 9: Measurement of exposure dose of the human model.

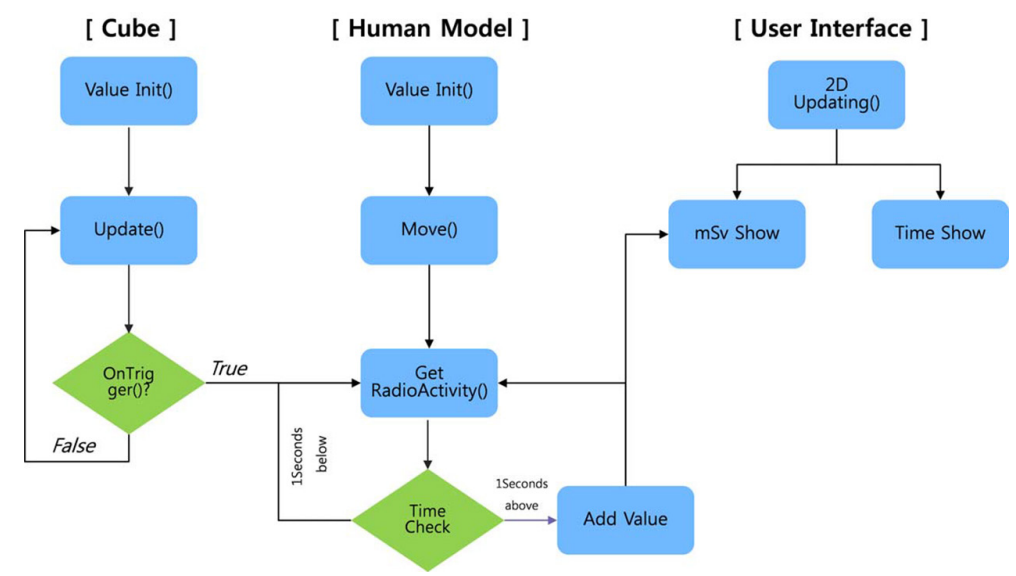

Figure 10: The algorithm of exposure dose measurement in virtual environments.

Further, the cube has functions of Value Init, Updataing, and OnTrigger. These functions play a role in evaluating collision of the human model and dose distribution. The human model has functions of Value Init, Mode, Get RadioActivity, and Time Check. These functions have a part in measuring exposure dose of workers in the duration of their working. The user interface has functions of 2D Updating, $\mathrm{mSv}$ Show, and TimeShow. The functions of user interface play a role in checking frames of the programme and in calculating the accumulated exposure dose and time.

\subsection{Method of exposure dose assessment}

The procedure of exposure dose assessment is shown in Fig. 11. As seen here, execution of MCNP produces the dose distribution. Cubes $(50 \mathrm{~cm} * 50 \mathrm{~cm} * 50 \mathrm{~cm})$ are built and painted with material colours by values of dose distribution. The built cubes are interrelated with parent cubes. Once a decommissioning scenario starts, time and exposure dose are checked when the human model moves. When the decommissioning scenario stops, duration of time and accumulated exposure dose are recorded. 


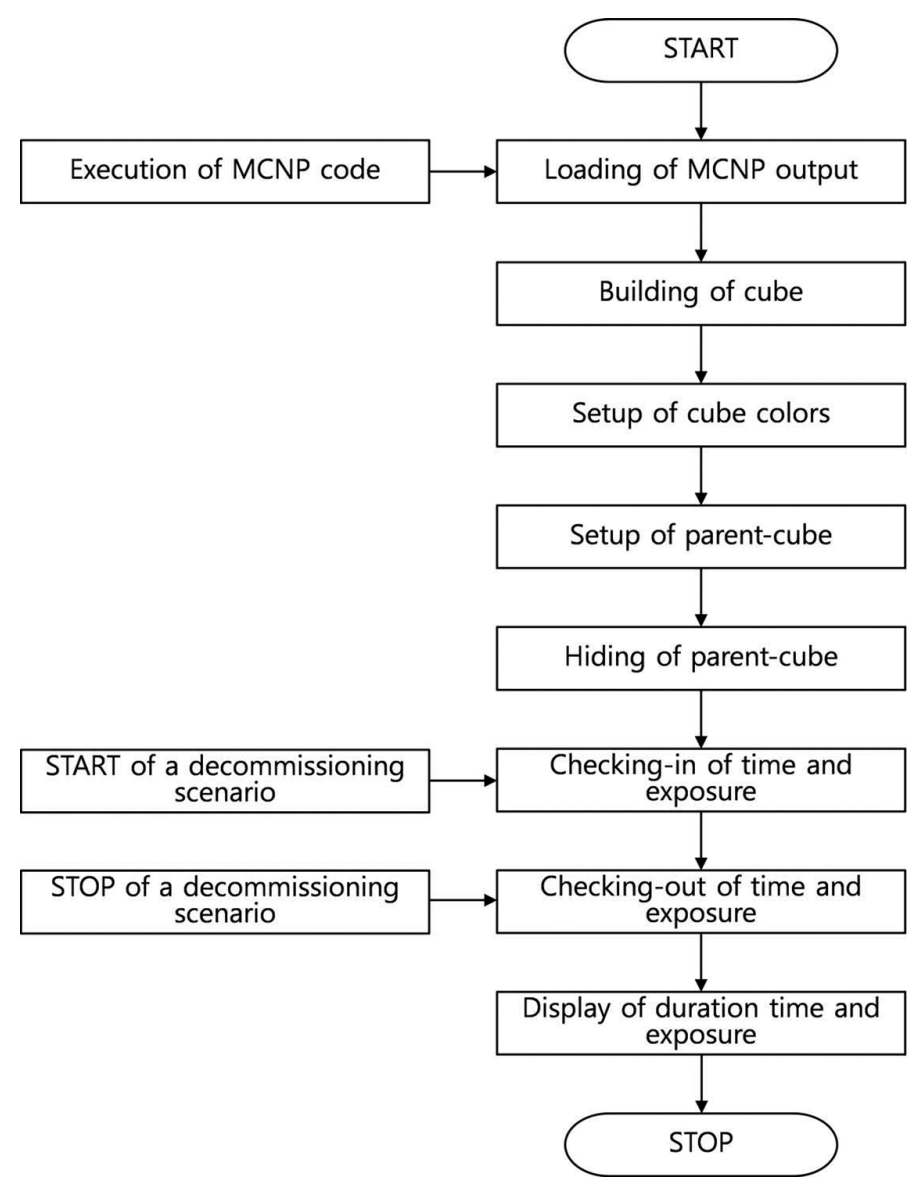

Figure 11: The procedure of exposure dose assessment.

\section{TEST AND RESULTS}

The scenario of equipment installations for dismantling a reactor pressure vessel was selected to test the feasibility of the evaluation methodology and system. The equipment required to dismantle a reactor pressure vessel includes band saw, circular saw, gantry manipulator, turntable, and waste container, as presented in Fig. 12.

There are three persons in the equipment installation experiment, including subject $\mathrm{A}$, subject B, and subject C. Subject A is a crane operator; subject B is a worker who checks equipment installation on the reactor's upper floor; and subject $\mathrm{C}$ is a rescue worker who takes care of the injured worker in the middle of checking equipment of the reactor's upper floor. As shown in Fig. 13, an accident was supposed to occur after the installation of the turntable and circular saw.

Figure 14 depicts that the assessment system is executing in emergency mode because of an abnormal accident from operational errors. Figure 15 illustrates that in view of monitoring, subject B is struck by equipment operated by subject A. In case of emergency mode, subject $\mathrm{A}$ is waiting without operation of the crane, subject $\mathrm{B}$ is in the situation of being struck by equipment, and subject $\mathrm{C}$ is supposed to go down to the accident spot to rescue injured subject B. 

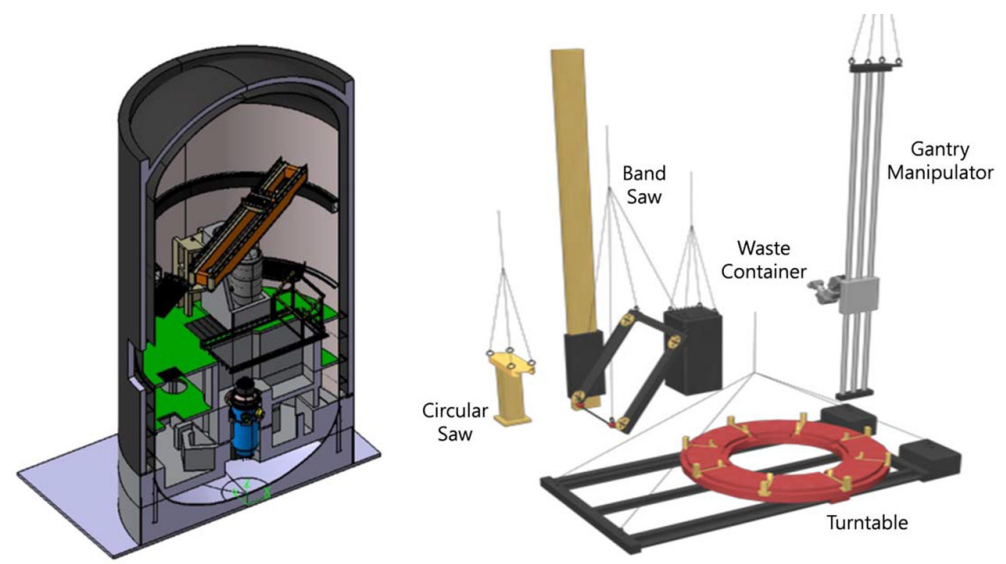

Figure 12: Installation of the equipment to dismantle a reactor pressure vessel.

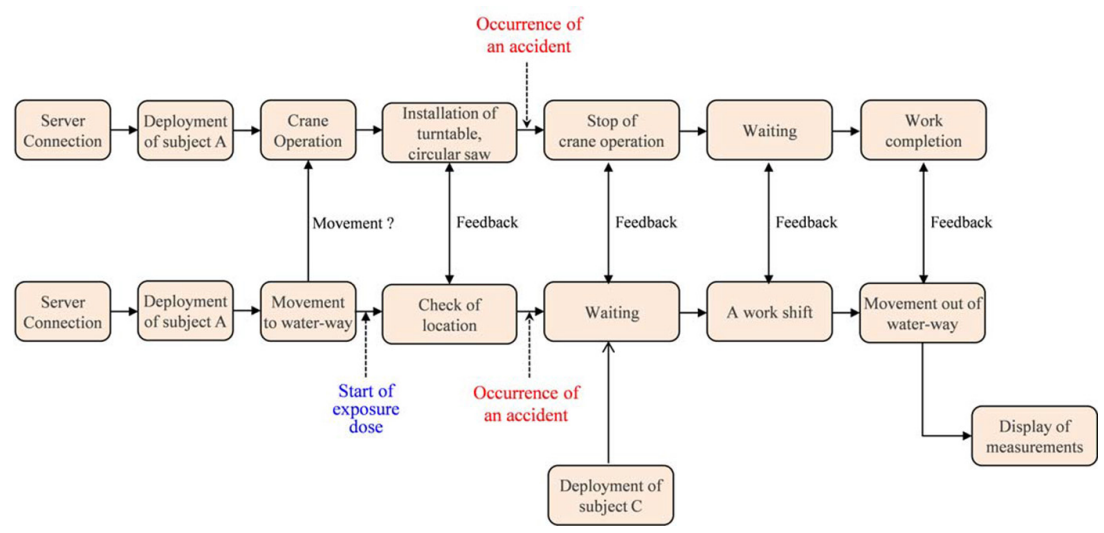

Figure 13: The accidental scenario in equipment installation.

On the basis of the input scenario, the performance test of the evaluation methodology was carried out as shown in Fig. 8. According to the equipment installation procedure, subject B went down the floor and subject A put down the equipment. In the middle of installing equipment, an accident occurred, whereby a worker was struck by the equipment. At this time, subject $\mathrm{C}$ went down to the floor where the accident occurred and returned with the injured worker.

\section{CONCLUSIONS}

This work aimed to simulate scenarios of decommissioning in order to measure and assess exposure dose of workers. To assess exposure dose of workers during decommissioning of nuclear facilities before decommissioning activities are undertaken, a method of simulation assessment was developed in virtual radiological environments.

However, this work was developed as a simulation tool for single-subject mode. Subsequently, the simulation environment for multi-subject mode will be upgraded by simultaneous modules with networking environments. Then, a much more practical method will be devel- 


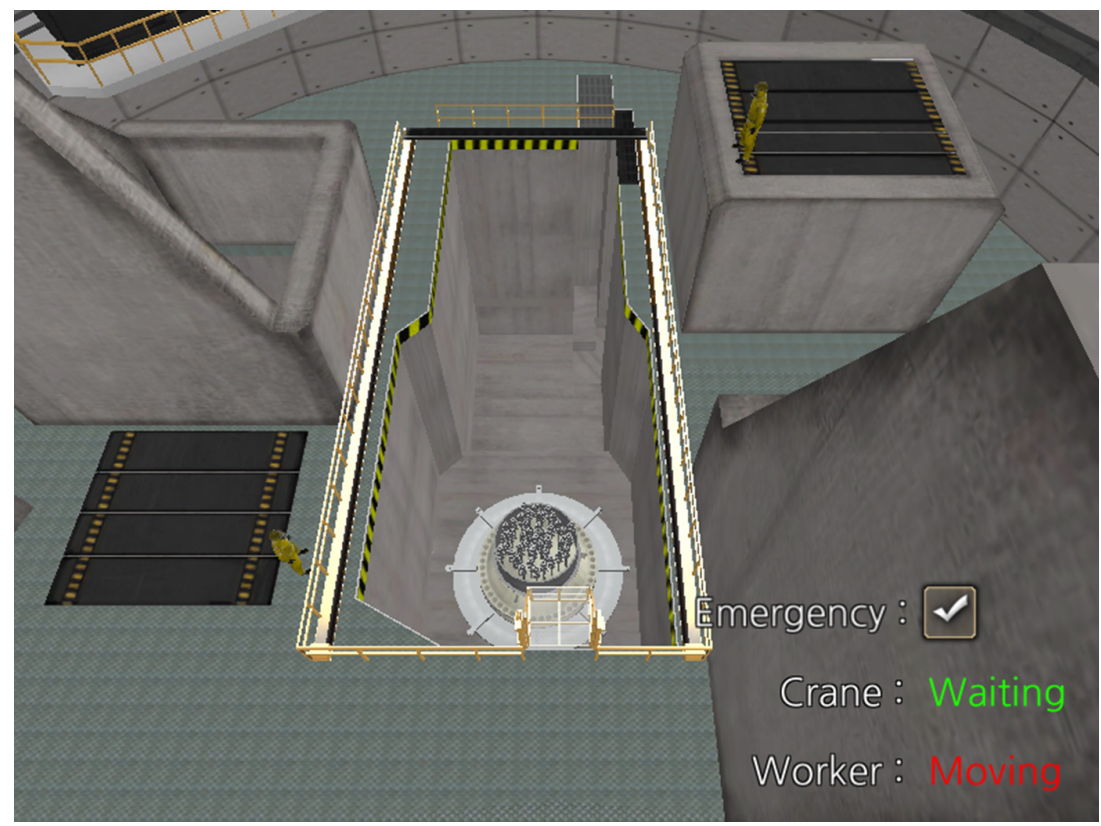

Figure 14: Operation of the assessment system in abnormal mode.

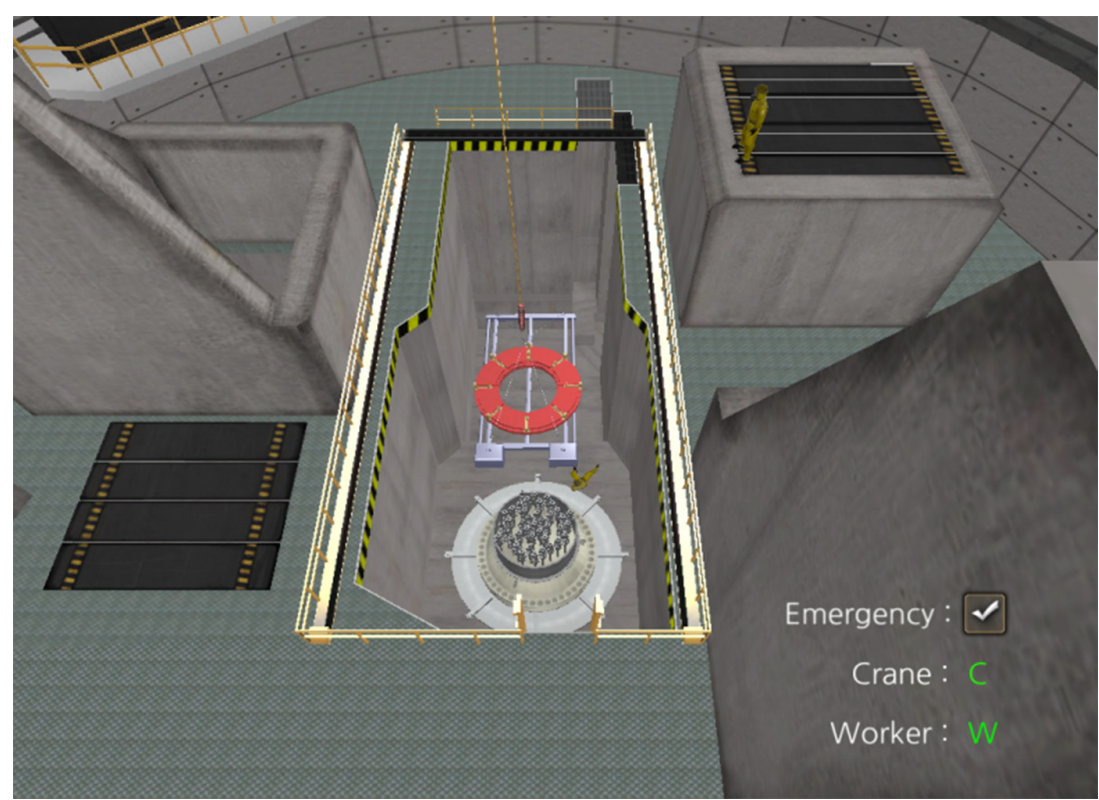

Figure 15: The situation in which a subject is struck by equipment. 


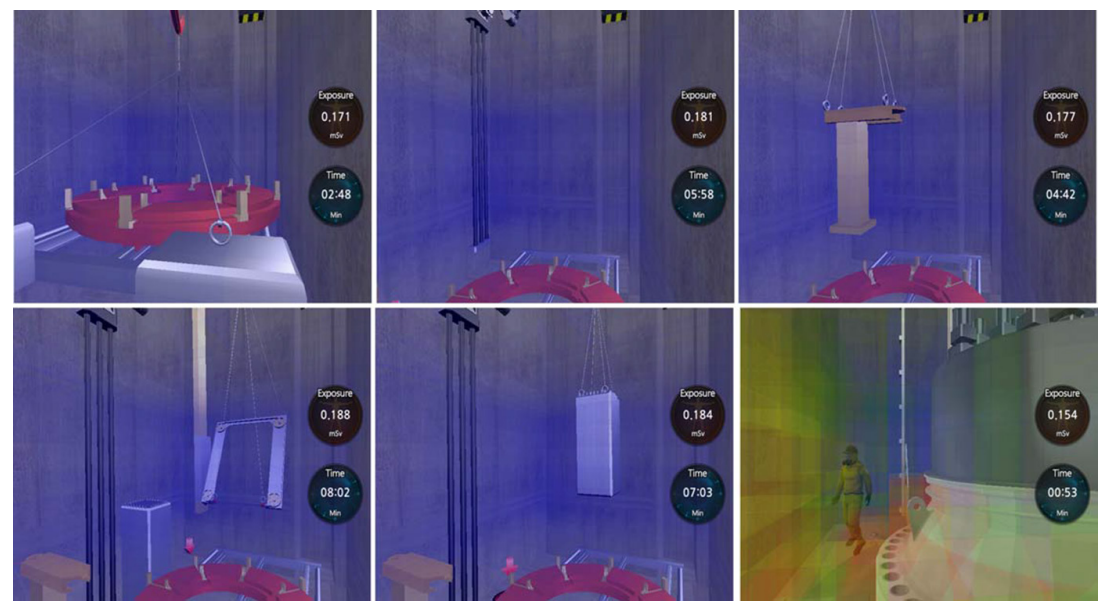

Figure 16: The performance test of an abnormal accident.

oped by changing the number of workers and duration of time under any decommissioning circumstance. It is expected that this method will make it possible to efficiently establish the ALARA plan for decommissioning nuclear facilities.

\section{ACKNOWLEDGEMENT}

This work was supported by the Nuclear Research and Development Program through the National Research Foundation of Korea funded by the Ministry of Science, ICT and Future Planning.

\section{REFERENCES}

[1] IAEA, Decommissioning of nuclear power plants and research reactors, IAEA Safety Series No. WS-G-2.1, 1999.

[2] Jeong, K.S., Choi, B.S., Moon, J.K., Hyun, D.J., Lee, J.H., Kim, I.J., Kim, G.H. \& Seo, J.S., The digital mock-up system to simulate and evaluate the dismantling scenarios for decommissioning of a NPP. Annals of Nuclear Energy, 69, pp. 238-245, 2014. http://dx.doi.org/10.1016/j.anucene.2014.02.020

[3] Jeong, K.S., Choi, B.S., Moon, J.K., Hyun, D.J., Lee, J.H., Kim, I.J., Kim, G.H., Seo, J.S., Jeong, S.Y., Lee, J.J., Song, H.S. \& Lee, S.H., Real-time assessment of exposure dose to workers in radiological environments during decommissioning of nuclear facilities. Annals of Nuclear Energy, 73, pp. 441-445, 2014.

http://dx.doi.org/10.1016/j.anucene.2014.07.027 